\title{
A ficção de António Lobo Antunes: Uma legião de sons dentro do silêncio
}

\section{The fiction of António Lobo Antunes: A legion of gibberish inside silence}

Evelyn Blaut Fernandes [blauteve@gmail.com]

Brasil

\section{RESUMO:}

Num episódio do Evangelho de São Lucas, Jesus se encontra com um homem possuído por espíritos malignos e pergunta por seu nome. "O meu nome é legião", responde, "porque somos muitos". Pois é este o título do romance que António Lobo Antunes publicou em 2007. O meu nome é Legião começa como um relatório policial que descreve a vida de uma gangue numa zona a que se chama simplesmente Bairro e que pode evocar qualquer bairro periférico de uma grande cidade, embora seja um bairro afastado de Lisboa. O inquérito redigido por um policial desiludido relata os atos violentos cometidos por oito jovens ao longo de uma madrugada. Este artigo reflete sobre este mosaico de múltiplas vozes que revela as desigualdades e a violência urbana, mas também questiona qual é, de fato, o mal que invade como demônios.

\section{Palavras-chave:}

Ficção portuguesa contemporânea; violência urbana; pós-colonialismo

\begin{abstract}
:
In an episode of Luke's Gospel, Jesus meets a naked and disfigured man, haunted by evil spirits, and asks for his name. "My name is Legion", he replies, "for we are many". The novel My name is Legion, published by António Lobo Antunes in 2007, begins as a police report, which describes the life of a gang in an area simply called Bairro (neighborhood). It can evoke any peripheral neighborhood of a big city, although it is around Lisbon. The investigation report, written by a disillusioned police officer, accounts the violent acts committed by eight young offenders during one dawn. The novel turns into a story of multiple voices, creating a mosaic of contrasts on injustice and pain. Among them, we hear versions by kids who were unloved, abused, excluded in childhood. After all, the book, which deals with inequalities (racial, social, geographical), urban violence and evil that invades as demons, also speaks of love for humanity and compassion.
\end{abstract}

\section{KEYWORDS:}

Contemporary portuguese fiction; urban violence; post-colonialism 
Uma certa canção composta por Mac Davis e gravada por Elvis Presley em 1969 não parava de ecoar na minha cabeça enquanto lia O meu nome é Legião. Apesar de mencionar a fria e cinzenta cidade de Chicago, In the ghetto fala sobre bocas famintas, crianças desamparadas, pessoas que preferem virar a cara e olhar para o outro lado, um garoto pobre que brinca na rua. Enquanto a fome aperta, a sua ira cresce. Ele passa a vagar pelos arrabaldes à noite, aprende a roubar e a lutar, até que, numa noite de desespero, ele compra uma arma, rouba um carro, tenta fugir, mas não chega longe. E uma multidão se amontoa à sua volta para vê-lo morrer. Em Chicago ou em Lisboa, o gueto "convoca todos os demónios, da miséria à criminalidade", como diz Pedro Mexia (2011) sobre o livro de António Lobo Antunes, "passando pelo envelhecimento e [pelo] racismo" (p. 395).

O meu nome é Legião parte de um relatório policial cujos interrogatórios vão dando lugar a interrogações. O objetivo desta missão policial é o de reconstituir o percurso e os atos violentos de adolescentes que vivem no "território das barracas", das “[q]uintas e palacetes abandonados, entre baldios e árvores ressequidas, agora invadidos por hortas e galinhas e construções improvisadas" (Mexia 2011: 396) entre "becos desertos e a tralha ao acaso das pessoas que fogem" (Antunes 2007: 147). O relatório dá conta do furto de dois carros "pelo método denominado da chave-mestra" (id., p.13) realizado por oito jovens com "idades compreendidas entre os 12 (doze) e os 19 (dezanove) anos", que vivem no Bairro 1º de Maio "infelizmente conhecido pela sua degradação física e inerentes problemas sociais" (id., p. 13), um "bairro de construções clandestinas na periferia de Lisboa, mais concretamente a noroeste da cidade, habitada por mestiços e negros oriundos das chamadas ex-colónias” (id., p. 320). Quem escreve este relatório é Gusmão, policial em sua última missão, homem solitário que busca reunir depoimentos de outros personagens que, de uma forma ou de outra, estão ligados ao destino destes jovens suspeitos por "vandalismo ou situação natural?" (id., p. 13).

Os suspeitos são figuras que "v[ê] $\mathrm{m}$ do mundo, exite[m] no texto e volta[m] a actuar no mundo" (Barrento 2009: 122), incorporando, portanto, "um princípio de vida” (id., p. 124). Como formas fantasmáticas, estas figuras vivem entre "aquilo que [] apavora, o que não aceito, o horror" (Antunes 2007: 94). À apresentação, segue a descrição do grupo: "o chamado Capitão de 16 (dezasseis) anos mestiço, o chamado Miúdo de 12 (doze) anos mestiço, o chamado Ruço de 19 (dezanove) anos branco[,] o chamado Galã de 14 (catorze) anos mestiço", “o chamado Guerrilheiro de 17 (dezassete) anos mestiço, o chamado Cão de 15 (quinze) anos mestiço, o chamado Gordo de 18 (dezoito) anos pretoe o chamado Hiena de 13 (treze) anos mestiço" (id., p. 14). O fato de serem apresentados por alcunhas (pejorativas), e não por nomes, denota uma espécie de anonimato, de identidades suspensas. Além disso, Gusmão salienta

a importância do chamado Ruço ser o único caucasiano

(raça branca em linguagem técnica)

e todos os companheiros semi-africanos e num dos casos negro e portanto mais propensos à crueldade e violência gratuitas o que conduz o signatário a tomar a liberdade de questionar-se preocupado à margem do presente relatório sobre a justeza da política de imigração nacional (id., p. 14). 
Esta observação do policial leva-me a «codificar as condições de surgimento e de manifestação da questão da raça» que o filósofo e cientista político Achille Mbembe denomina "o Negro". No contexto (pós-)colonial, “a razão negra” designa um conjunto de discursos e de práticas cujo trabalho diário consistiu (e, em muitos casos, ainda consiste) "em inventar, contar, repetir e pôr em circulação fórmulas, textos, rituais, com o objectivo de fazer acontecer o Negro enquanto sujeito de raça e exterioridade selvagem, passível, a tal respeito, de desqualificação moral e de instrumentalização prática" (Mbembe 2014: 58). O "Negro" é, neste sentido, a construção de uma "[f]igura em excesso de qualquer figura e, portanto, fundamentalmente não figurável", constituindo "o exemplo total deste ser-outro, fortemente trabalhado pelo vazio, e cujo negativo acabava por penetrar todos os momentos de existência”. Achille Mbembe nota que essas figuras inventadas representam "a marca dos povos isolados e não sociáveis, que combatiam odiosamente até à morte, se desfaziam e se destruíam como animais” (id., p. 28).

Caracterizando o criminoso como um ser estranho, a ordem social concebe o delito como uma anomalia. Através de uma diferenciação dos ilegalismos, uma pedagogia do poder define a delinquência como uma violação da lei. Mais do que criminosos, porém, estes "delinquentes" (como são chamados) são socialmente inaceitáveis, uma vez que a própria organização social da cidade encaminha à criminalização de atos e raças, mas, sobretudo, a uma incoerente desumanização de seres humanos. Vistos como viveiros de criminosos por "pessoas que preferem virar a cara e olhar para o outro lado", estes (não-)lugares são presumivelmente considerados geradores de ira, onde as pessoas, dadas as circunstâncias, podem tornar-se corrompíveis. Consequentemente, estes oito jovens são isolados através de uma biopolítica que organiza corpos em zonas afastadas do centro da cidade.

As incursões dos jovens que compõem uma cartografia (sub)urbana de Lisboa podem ser reflexo da viagem "lúmpen-atlântica" (id., p. 90), uma vez que as suas deambulações vão expondo os contrastes e o antagonismo dos espaços que, embora se toquem, permanecem separados por um fosso sócio-econômico. Livro de guetos e de becos sem saída, O meu nome é Legião é um retrato da persistente e miserável mentalidade heterotópica (pós-)colonial que, de geração em geração, renasce e renova a concepção de que "todos os pretos roubam", "diz-se que todos os pretos roubam” (Antunes 2007: 217), ou seja, “o que herdámos de África macacos que nos mentem, nos roubam" (id., p. 137).

Por falar em guetos, lembro-me de um conto também escrito por António Lobo Antunes, e ilustrado por Vitorino, que pode ser, à primeira vista, catalogado como infantil. Apesar de o formato aproximar-se do gênero, não creio que o texto tenha sido escrito para crianças. Na história do hidroavião, dois amigos vindos de África vivem às margens de Lisboa numa "barraca de tábuas costuradas com arame e reforçadas de placas de cartão, com um pedaço de zinco a servir de telhado" (Antunes 1994: 7), rodeada por "ralhos, estalos de púcaros de folha, choros a fosforescerem aqui e acolá, pavios de azeite em amparos de tela, a labareda da Siderurgia, no meio de tubos doirados, inundando as trevas de carvão” (id., p. 14). É este o cenário para evasão das pessoas que chegam em Lisboa "fugidas à guerra" a "martela[r] cabanas num baldio de ervas frentes aos vapores do Tejo, entre armazéns ao abandono” (id., p. 7) que contrastam com "monumentos, estátuas, igrejas, o carrocel do oito, bairros de ricos, tudo" (id., p. 23).

É neste sentido que a consciência ocidental do Negro, designada por Mbembe, pode ajudar a compreender "uma realidade que [...] é exterior e que [...] tende a situar relativamente a um 
eu tido como centro de qualquer significação. A partir desta posição, tudo o que não é idêntico a si, apenas pode ser anormal" (Mbembe 2014: 58) ou arquétipo de "raças inferiores, amarelos peles-vermelhas indianos" (Antunes 2007: 66) ou de "má rês", como Gusmão diz ser a

mestiça e portanto má rês, apontem-me um preto como deve ser, trabalhador, honesto e por mais que se esforcem não encontram nem um [...] de modo que cá os temos a norte de Lisboa enchendo as quintas abandonadas [...] a acenderem fogueirinhas com sobras de mobília enquanto os netos em bando na Amadora com manias de branco vestidos como uma caricatura de nós que ninguém de bom senso se atreveria a usar a menos que pretendesse ser tomado por um louco ou um chulo e portanto que podia eu esperar da mestiça (id., pp. 223-224).

Ao seu relatório Gusmão imiscui “uma breve digressão" a que, logo em seguida, pede perdão por "inserir num documento oficial e em papel do Estado este desabafo importuno e este desejo absurdo de companhia" que também dá conta do quanto o incomoda o "silêncio do costume" e a "indiferença das coisas" (id., p. 15). Assim é feito o seu relatório policial, que mistura detalhes objetivos com memórias da vida pessoal, além da observação de "que vigaristas não faltam" (id., p. 16) e que, portanto, “o que não falta são crimes” (id., p. 20), talvez porque, pensa Gusmão, “o que este país tem de sobra são mestiços e pretos” (id., p. 40) e este país, já se sabe, não "perde tempo com mestiços" (id., p.164). Por isso, no Bairro, "o que não faltava eram quartos, sujidade, trastes [...] velhos [...], os brancos sem se chegarem” (id., p. 116) aos pretos. Aliás, numa visita ao Bairro $1^{\circ}$ de Maio, Gusmão observa de longe em longe pretos (ia escrever negros olha a cerimónia, pretos) (id., p. 64-65).

São chamados negros, pretos, macacos, porque, através de um processo de disseminação e de inculcação, uma "enorme ganga de disparates, de mentiras e de alucinações tornou-se uma espécie de invólucro exterior cuja função foi, desde logo, substituir-se ao seu ser, vida, trabalho e linguagem". Tal revestimento exterior estratifica-se, transformando um conjunto de membros numa "casca calcificada" (Mbembe 2014: 77). Negros e pretos são palavras que, de um ponto de vista histórico, remetem de modo similar a uma fantasmagoria - o estatuto da aparência, a simbologia das cores. É este processo fantasmagórico que transforma "pessoas de origem africana em 'negros', isto é, em corpo de exploração e em sujeitos de raça” (id., p. 78), de onde deriva a criação de estereótipos e de um ódio sádico que não se refere apenas aos períodos de colonização e de guerra colonial. Ele é, acima de tudo, uma consequência histórica. Além de espectros do Atlântico (apud Mbembe 2014: 78), esta legião de mestiços e negros é também uma produção metamórfica perversa que converte um grupo de pessoas tanto em objeto de práticas de possessão quanto em figura daquele que deve ser mantido à distância. Por isso, procurando evitar generalizações, os policiais de agora são assassinos uniformizados. Enquanto enunciados e estigmas procuram interpretar a pobreza e a espoliação de povos que, de certo modo, ainda vivem sequelas de pilhagem sequestro, a violência colonial passou a ser travada nos bairros degradados da periferia de uma "sociedade semiperiférica” (Santos 1990: 14).

Ao mobilizar uma noção de "negro" que reifica homens e comunidades, estabelece-se uma zona de indiferenciação entre homem e animal. Neste sentido, outra forma de segregação é a animalização, ou seja, o gesto de atribuir características, atitudes ou comportamentos próprios de animais a seres racionais. Em outras palavras, dizer "que os pretos animais" (Antunes 
2007: 159) significa tirar-lhes a razão, retirar do homem o que é inerente ao humano e "perseguir na vida de hoje os sinais que indicam o regresso do colonialismo ou a sua reprodução e a repetição nas práticas contemporâneas" (Mbembe 2014: 267), como o belicismo que continua a ter o contorno de uma "empresa de extermínio" (apud Mbembe 2014: 269). Mas significa também perpetuar uma fissão maniqueísta, e esta, sim, diabólica, que aponta brancos como civilizados e negros como selvagens. Os jovens do Bairro $1^{\circ}$ de Maio são representados como "aqueles a quem é recusado o direito de ter direitos [...] condenados a viver em toda a espécie de estruturas de reclusão". São portugueses, descendentes de africanos, e, por isso, considerados clandestinos, intrusos, escória que não vale a pena salvar. São crianças assassinadas por policiais. São "o resultado de um brutal trabalho de controlo e de selecção cujos pressupostos raciais são bem conhecidos" (Mbembe 2014: 296).

Há, inclusive, quem defenda a relação entre insalubridade e criminalidade: na verdade o número de criminosos aumenta porque, para além de crescerem num ambiente hostil e insalubre, são hostilizados quando ganham outras bandas da cidade, que acaba por ser, algumas vezes, a única ocupação para quem é vedado ocupar espaços (institucionais) no mundo. Neste sentido, os oito jovens do Bairro $1^{\circ}$ de Maio caracterizam metonimicamente um gueto, uma vez que eles representam uma comunidade forçadamente periférica.

Através da justaposição de perspectivas, vozes, tempos e registros, o leitor tem acesso aos pontos de vista de alguns personagens, como a mãe do Miúdo, ou a irmã do Hiena, ou a amante do Gordo. Enquanto isso, a polícia vai fechando o cerco e matando alguns dos integrantes da gangue, talvez com tantos requintes de crueldade quanto a tropa durante a guerra colonial, porque "no fim de contas pode ser" "que África igual ao Bairro" (Antunes 2007: 200). África = Bairro pode significar, portanto, a perpetuação "da mortalha que os Negros continuam a carregar do fundo do túmulo: a escravidão" (Mbembe 2014: 54). Por outras palavras, o Bairro $1^{\circ}$ de Maio é um simulacro dos subúrbios de Lisboa, constituído como ponto de ancoragem destes jovens, mas que não deixa de ser também uma espécie de campos deturpados e destinados a "povos submetidos à colonização e à segregação, que tentam libertar-se das hierarquias raciais" (id., p. 63). O Bairro pode ser também o simulacro de um país com um bom punhado da sua realidade por nela se prefigurarem relatos e retratos de vidas que partilham a dinâmica da violência na cidade, consequência plausível de um processo de descolonização mal guiado, o que remete a um passado indelevelmente marcado por atrocidades dificilmente superadas.

O romance, porém, põe em xeque a habitual supremacia branca através de uma convivência revirada de ressentimentos, como sucede com Gusmão quando vai viver, a mando do seu chefe, sob disfarce no Bairro, na casa de uma mestiça a fim de obter informações mais precisas sobre o cotidiano e as atividades criminosas dos jovens. Relutante em reconhecer, devido a hábitos racistas inveterados, o policial paulatinamente passa a ver a mulher com quem vive de modo diferente, transformando a repulsa inicial em desejo de proteção. Embora nunca confesse, sente afeição pela mulher de quem se recusa a pronunciar o nome, insistindo em chamá-la de preta. Este cenário expõe uma sociedade de guetos que, só pontualmente através do exercício do afeto, permite o encontro de seres humanos e não o conflito de raças.

No final do romance, a narrativa é entregue pela primeira vez a dois dos jovens que apresentam uma outra versão dos acontecimentos, dando conta de outras dores, como 
maus-tratos familiares, a ausência materna, a falta de afeto, os abusos sexuais ocorridos na instituição a que foram confiados pelas pessoas que deveriam protegê-los (um médico com a conivência e apoio de um vigilante). Um destes jovens é Hiena (cuja morte foi anteriormente narrada pela irmã), o mais jovem do bando. Ele toma a palavra, pelo recurso da analepse, e mostra, também através da sua perspectiva, que o medo e a valentia coexistem obliquamente em cada homem: "Não tenho medo de morrer. Os guardas têm medo de morrer e têm medo de mim" (Antunes 2007: 357). "Não tenho medo de morrer. Não tenho medo de vocês. Vou dizer um segredo. Tenho medo do escuro. Era a brincar. Não tenho. Tenho. Não tenho" (id., p. 361).

Tocam-se, assim, dois espaços contíguos que emanam uma sobrevivência precária, compondo um Portugal também feito de tensões raciais e identitárias. Estes dois espaços são, ao mesmo tempo, a descrição de um ambiente suburbano e a recriação de um cenário disfêmico, do qual sobressaem barracas, "cachorros vadios sempre à cata de sobras” (Antunes 1994: 16) e "os pântanos do Tejo" (id., p. 12) numa Lisboa arrasada pela vontade de fuga e de pertencimento.

Gostaria, entretanto, de regressar à fala que se repete, com pequenas variações, nos Evangelhos de Marcos, Mateus e Lucas: “Legião é o meu nome, porque somos muitos”. Esta fala compõe uma cena de exorcismo, ritual que expurga os males de um corpo. Por um lado, pode-se dizer que Gusmão, estando do lado da lei, é o responsável por eliminar alguns elementos que perturbam uma certa ordem social das coisas. Por outro lado, se "somos muitos", quem, neste contexto, são os verdadeiros demônios? Como diz o título de um filme de Wolfgang Staudte, os assassinos estão entre nós (1946). Ou ainda, como indagaria Fernão Mendes Pinto, quem dentre nós é o selvagem? Nas palavras de António Lobo Antunes, "os mestiços e o branco em torno dos homens, vendo bem os brancos tão selvagens quanto os outros, pensava que não e enganei-me" (Antunes 2007: 165).

Com efeito, está-se diante do que Zygmunt Bauman (1998) denomina criminalização dos consumidores falhos, ou seja, de uma massa de excluídos que não têm recursos para acessar o mercado de consumo. Segundo o sociólogo, segrega-se "aqueles cujos meios não estão à altura dos desejos" (p. 57), punindo-os ou tornando-os, o quanto possível, invisíveis ou, pelo menos, "uma presença silenciosa”, para citar um título de José Ramos Tinhorão (1997). Esta seletividade punitiva não só transforma adolescentes em outsiders, como remete ao que desta "classe de criminosos" foi excluído. É o que se percebe ao ler O meu nome é Legião em cujo enredo se pode ouvir os sons dentro do silêncio de alguns personagens que pontualmente tomam a palavra para narrar os seus fatos e as suas lembranças, criando um mosaico de contrastes. Dentre elas, são as versões dos miúdos que ouvimos, como foram mal-amados e maltratados, gerando uma celeuma fantasmagórica destes que passam a ser vistos e apontados como delinquentes.

Afinal, o livro traça perfis de figuras provenientes da diáspora de uma ex-colônia falida e seus descendentes relegados à miséria de bairros decadentes e degradados. Estes perfis acabam por compor um retrato contemporâneo, também feito de jovens deserdados que, no fundo, desejam viver numa "casa a sério", não "no Bairro" (Antunes 2007: 360). O Hiena, por exemplo, se "desse na gana pensar começava a correr até ficar muito longe do Bairro onde ninguém desse por [ele]. Acha-se sempre um sítio para dormir. Um prédio ao abandono. Uma entrada de estábu- 
lo. Um celeiro. Não precis[a] dos outros" (id., p. 361). Hiena aprendeu a sobreviver dentro da própria solidão e do abandono. Mas deseja escapar desta esfera biopolítica na qual se encontra submerso.

Os maniqueísmos aqui apresentados - polícia versus bandido, branco versus preto - estão imbuídos de uma mentalidade colonial e arreigadamente racista que faz de Gusmão tão vítima deste sistema quanto os chamados "delinquentes". A formação afetiva deste agente de polícia também é feita de ligações de desafeto, que "por família entend[e] não apenas os [s]eus pais e o [s] eu padrasto mas a [sua] ex-mulher e a [sua] filha", com quem mantém uma relação restrita à "esperança de um diálogo que não tivemos e continuamos a não ter" (id., p. 34; cf. Fernandes 2015: 59). O meu nome é Legião dá visibilidade aos reais problemas das personagens, muito similares aos reais problemas dos seres humanos, ao mesmo tempo em que procura reconciliar as múltiplas facetas humanas. A estigmatização, a falta de serviços, de ocupação e de amparo, a privação do direito à dignidade podem ter consequências na saúde pública, gerando uma agressividade vista como rebeldia que pode culminar em atos criminosos. Consequentemente, o agente responsável pelo inquérito policial realiza um trabalho que pretende coagir a criminalidade imediata no espaço público, o que também constitui fator de seletividade punitiva orientada pelos padrões de vulnerabilidade dos pré-concebidos preceitos guiados (simultaneamente) por cor da pele e situação financeira. Sem propriedade, afastados de uma rede social de proteção e privados do que há de mais elementar, estes jovens cirandam, tanto quanto Gusmão, na indústria do crime.

Apesar de serem condenados pelos atos violentos praticados, estes jovens carregam histórias também marcadas por misérias, dores e ausências. Tanto o policial prestes a se aposentar quanto esse grupo de oito jovens, que vivenciam privações materiais e afetivas, provêm de fantasmas do passado, do abandono, da solidão, do sofrimento, da injustiça, da ausência, de debilidades, de abusos, de violência. Todos eles são figuras confrangidas pela vida que têm, pela vida que não tiveram, pela vida que não têm. Todos eles compõem irremediavelmente uma legião de espectros.

\section{Referências bibliográficas}

Antunes, A. L. (2007). O meu nome é Legião (3a ed./ 1 a ed. ne varietur). Lisboa: Dom Quixote.

Antunes, A. L., \& Vitorino (il.). (1994). História do hidroavião. Lisboa: Dom Quixote.

Auerbach, E. (1997). Figura. São Paulo: Ática.

Barrento, J. (Org.) (2009). O que é uma figura? Diálogos sobre a obra de Maria Gabriela Llansol na Casa da Saudação. Lisboa: Mariposa Azual.

Bauman, Z. (1998). O mal-estar na pós-modernidade. Rio de Janeiro: Jorge Zahar.

Fernandes, E. B. (2015). A ficção de António Lobo Antunes: da coreografia dos espectros à caligrafia dos afectos. Universidade de Coimbra: Faculdade de Letras da Universidade de Coimbra. Tese de Doutoramento. Martins, R. C. (2011). Que farás, América, quando arder tudo? In A. P. Arnaut (Ed.), António Lobo Antunes: a crítica na imprensa (1980-2010): cada um voa como quer. Coimbra: Almedina. 
Mexia, P. (2011). As vozes. O Meu Nome É Legião. In A. P. Arnaut (Ed.), António Lobo Antunes: a crítica na imprensa (1980-2010): cada um voa como quer. Coimbra: Almedina.

Mbembe, A. (2014). Crítica da razão negra. Trad. M. Lança. Lisboa: Antígona.

Santos, B. de S. (1990). Onze teses por ocasião de mais uma descoberta de Portugal. Oficina $n^{\circ} 21$. Coimbra: Publicação seriada do Centro de Estudos Sociais, Universidade de Coimbra.

Tinhorão, J. R. (1997). Os negros em Portugal: uma presença silenciosa. Lisboa: Caminho. 